\title{
Publisher Correction: Shape and fluctuations of frustrated self-assembled nano ribbons
}

Mingming Zhang ${ }^{1,2}$, Doron Grossman (1) ${ }^{1}$, Dganit Danino ${ }^{2} \&$ Eran Sharon ${ }^{1}$

Correction to: Nature Communications https://doi.org/10.1038/s41467-019-11473-6, published online 8 August 2019.

In the original version of this Article, reference 34 was incorrectly given as: "Danino, D. Emerging microscopy methods in colloid science. Curr. Opin. Colloid Interface Sci. 17, 316-329 (2012)" instead of the correct "Danino, D. Cryo-TEM of soft molecular assemblies. Curr. Opin. Colloid Interface Sci. 17, 316-329 (2012)". This has been corrected in both the PDF and HTML versions of the Article.

Published online: 13 September 2019

(c) Open Access This article is licensed under a Creative Commons Attribution 4.0 International License, which permits use, sharing, adaptation, distribution and reproduction in any medium or format, as long as you give appropriate credit to the original author(s) and the source, provide a link to the Creative Commons license, and indicate if changes were made. The images or other third party material in this article are included in the article's Creative Commons license, unless indicated otherwise in a credit line to the material. If material is not included in the article's Creative Commons license and your intended use is not permitted by statutory regulation or exceeds the permitted use, you will need to obtain permission directly from the copyright holder. To view a copy of this license, visit http://creativecommons.org/licenses/by/4.0/.

(C) The Author(s) 2019

\footnotetext{
${ }^{1}$ The Racah institute of Physics, The Hebrew University of Jerusalem, Jerusalem, Israel. ${ }^{2}$ CryoEM Laboratory of Soft Matter, Faculty of Biotechnology and Food Engineering, Technion-Israel Institute of Technology, Haifa, Israel. Correspondence and requests for materials should be addressed to E.S. (email: erans@mail.huji.ac.il)
} 